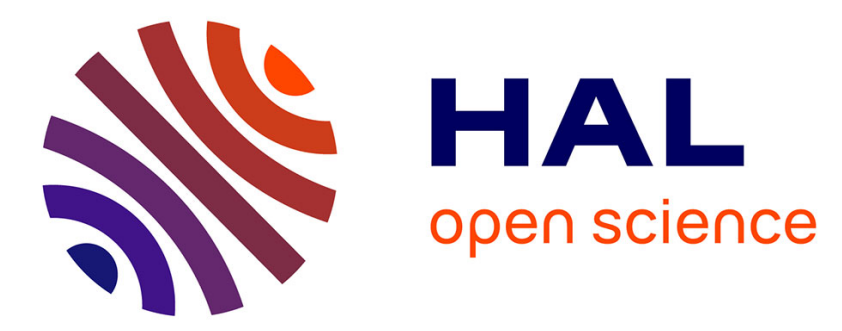

\title{
Under the risk of destructive event, are there differences between timber income based and carbon sequestration based silviculture? \\ Patrice Loisel
}

\section{- To cite this version: \\ Patrice Loisel. Under the risk of destructive event, are there differences between timber income based and carbon sequestration based silviculture?. Forest Policy and Economics, 2020, 120, pp.102269. 10.1016/j.forpol.2020.102269 . hal-02960259}

\section{HAL Id: hal-02960259 \\ https://hal.inrae.fr/hal-02960259}

Submitted on 5 Nov 2020

HAL is a multi-disciplinary open access archive for the deposit and dissemination of scientific research documents, whether they are published or not. The documents may come from teaching and research institutions in France or abroad, or from public or private research centers.
L'archive ouverte pluridisciplinaire HAL, est destinée au dépôt et à la diffusion de documents scientifiques de niveau recherche, publiés ou non, émanant des établissements d'enseignement et de recherche français ou étrangers, des laboratoires publics ou privés.

\section{(ㅇ)(1) $\$$}

Distributed under a Creative Commons Attribution - NonCommercial - NoDerivatives| 4.0 


\title{
Under the risk of destructive event, are there differences between timber income based and carbon sequestration based silviculture?
}

\author{
Patrice Loisel \\ MISTEA, Université Montpellier, INRAE, Institut Agro, Montpellier, France
}

\section{A R T I C L E I N F O}

\section{Keywords:}

Optimization

Calculus of variations

Optimal control

Faustmann value

Tipping age

Carbon sequestration

\begin{abstract}
A B S T R A C T
We consider the management of a mono-specific even-aged forest at the stand level. Optimal silviculture based on timber income and sequestered carbon income in an no risk case and a risky case are compared. In this study, using calculus of variations we discuss the validity of using a risk adjusted discount rate (a rate of natural risk added to the discount rate) or using a carbon adjusted discount rate (a rate of natural risk subtracted to the carbon discount rate) without risk to mimic the natural risk case in term of optimal thinnings. Except for very high risk rate values in the risky case, the optimal trajectory for carbon sequestration is very different from that obtained for the timber criterion. We show that without risk or with risk case but moderate risk rate, the optimal cutting age for sequestered carbon will be the senescence age. For higher risk rate the optimal cutting age for sequestered carbon may be more comparable to optimal timber cutting age.
\end{abstract}

\section{Introduction}

Until very recently, silviculture was mainly based on timber production. But the increasing concentration of carbon dioxide in the atmosphere has become a concern. Forests are seen as an opportunity to absorb significant amounts of carbon Forest management taking into account carbon stocks is therefore desirable: the quantities of carbon stored depend on the silviculture and in particular on cutting and thinning. As with timber production, the presence of risk, such as storm risk, can potentially modify silviculture based on sequestered carbon criteria.

For timber production in the absence of risk, (Faustmann, 1849) proposed a formalism based on the expected discounted income, which allows to determine the optimal rotation period. Many authors have been studying ((Schreuder, 1971), (Clark, 1976), (Haight et al., 1992)) the determination of optimal thinning and cutting age at the stand level. The impact of a destructive event risk (in this case the fire risk) on the optimal forest rotation was studied in (Reed, 1984). More recently concerning natural risk, (Staupendahl and Möhring, 2011) studied the impact of risk on the expected value of a forest stand for various hazard rate functions, (Loisel, 2011) examined the impact of density dependent growth on optimal cutting age, (Price, 2011) focused on the validity of using the rate of physical risk, added to the discount rate as a new adjusted discount rate. Impact of storm risk on optimal thinnings and cutting age are analyzed in (Loisel, 2014). The combined impact of storm risk and price uncertainty has been studied in (Rakotoarison and
Loisel, 2017). (Möllmann and Möhring, 2017) used the concept of expected losses in order to determine the optimal rotation. Using empirical material, (Deegen and Matolepszy, 2015) highlighted the complexity of forest management under storm risk.

Concerning the carbon sequestration, using a Hartman framework (Hartman, 1976) many authors ((Plantinga and Birdsey, 1994), (Creedy and Wurzbacher, 2001), (Gutrich and Howarth, 2007), (Liski et al., 2001)) considered the joint timber production and carbon sequestration, they analyzed the influence of carbon sequestration incomes on the optimal cutting age: it is optimal to increase the cutting age. In some circumstances, with carbon taxes (Van Kooten et al., 1995) or high carbon prices, (Price and Willis, 2011) showed that it may become optimal never to harvest forest stand. (Susaeta et al., 2014) analyzed influence of carbon price fluctuations on optimal cutting age. (Kaipainen et al., 2004) analyzed the influence of elongation of rotation length on carbon stock. (Assmuth and Tahvonen, 2018) studied optimal harvesting in even and uneven-aged forest. There is a lack of studies relatives to the $\mathrm{C}$ sequestration analysis and the prediction of the modification induced by natural risk on optimal thinnings and cutting age. In the present work, we model the impact of natural risk on optimal silviculture for carbon sequestration at the stand level. With Faustmann value based on the joint production of timber and carbon sequestration, the corresponding analysis will be subject to fluctuating economic environment (Susaeta et al., 2014), to avoid this influence we then choose to consider a criterion not impacted by carbon price i.e. the Faustmann value based on carbon sequestration alone. In our

E-mail address: patrice.loisel@inrae.fr. 
presentation we study the dependency of optimal forest management, in order to maximize forest sequestration, with respect to economic or risk parameter. In order to be as accurate as possible, our study is based on a forest growth model. Moreover in our presentation, from obtaining analytical expression of the criteria to optimize, we compare strategies that maximize carbon sequestration to those that maximize the timber income. The study presented is done at the stand level. The optimized strategies are set by dates and amplitudes for respacing and thinnings and of course the cutting age.

In Section 2, we first consider the reference case without the natural risk, which will be used for comparison. Based on a growth model we express under which sufficient conditions it is possible to predict the behavior of the cutting age with respect to physical or economic parameters. Secondly, based on the growth model, on the risk and tree damage models in case of natural risk, we analyze the impact of the natural destructive event on the behavior of cutting age. In Section 3, we successively analyze the optimal criterion and corresponding optimal trajectory without and with natural risk. We discuss the validity of using a risk adjusted discount rate (a rate of natural risk added to the discount rate) or using a carbon adjusted discount rate (a rate of natural risk subtracted to the carbon discount rate) without risk to mimic the natural risk case in terms of optimal thinnings.

\section{The optimization based on timber production}

\subsection{The forest growth}

We consider a forest stand. The design of the chosen model is describe in Appendix A. To resume, the forest growth is described by the evolution of the basal area $B$ is, for each initial condition $B_{0}$, given by:

$\frac{d B(t)}{d t}=g(r(t)) I(t)-e(t)$

where the RDI (Reineke Density Index) $r$ satisfies $r(t)=A B(t) \leq 1$, the harvesting control $e$ satisfies and the evolution of the tree height $H(t)$ is a given function independent of the silviculture, the increase of basal area of the forest stand at its peak of density $I(t)$.

We assume that $I(t), t>0$ and $g(r), 0<r \leq 1$ satisfy the following properties:

$\left(H_{1}\right): I($.$) is a positive, decreasing function of time t$.

$\left(\mathrm{H}_{2}\right): g($.$) is a positive, increasing, concave function of r$ such that $g$ $(r) \geq r$ for all $r, g(0)=0$ and $g(1)=1$.

$\left(H_{3}\right): H($.$) is a increasing function and \frac{H^{\prime}}{H}($.$) is a decreasing function$ of time $t$.

To finish the model description, the average tree height $H(t)$ is independent of the silviculture (thinning $e($.$) ), hence independent of B$.

We now consider specific trajectories which make a rule in optimization:

(i) $E^{0}\left(B_{1}\right)$, starting from the initial basal area $B_{0}$ at initial time satisfying $r(0)=A B_{0}<1$, reaching $B_{1}$ with $r_{1}=A B_{1} \leq 1$, we apply minimum cutting $e(t)=0$ until reaching the value $r_{1}$ for the RDI, then we apply the control $e_{r}(t)=g\left(r_{1}\right) I(t)$. Let denote $t^{0}\left(B_{1}\right)$ is the time needed to reach from the RDI $r(0)$ to $r_{1}$, from $e(t)=0$ for $t<t^{0}\left(B_{1}\right)$ Eq. (1) may be rewritten: $\frac{d r(t)}{g(r(t))}=A I(t) d t$. Hence integrating this equation between the initial time and $t^{0}\left(B_{1}\right)$ we obtain the following relation:

$\int_{r(0)}^{r_{1}} \frac{d x}{g(x)}=A \int_{0}^{t^{0}} I(u) d u$

Hence control may be summarized: $e^{0}\left(t ; B_{1}\right)=g\left(r_{1}\right) I(t) 1_{t>t^{\circ}\left(B_{1}\right)}$. We denote $B^{0}\left(t ; B_{1}\right)$ the corresponding basal area starting from initial basal area $B_{0}$ at initial time.

(ii) $\underline{E}\left(t_{0}, B_{0}\right)$, starting from the initial condition satisfying $r\left(t_{0}\right)=A B$ $\left(t_{0}\right) \leq 1$ we apply maximum cutting $e(t)=\bar{e}$. We denote $\underline{B}\left(t ; t_{0}, B_{0}\right)$ the corresponding basal area.

We also consider auxiliary problem which consist in seeking the maximum values reached by the basal area $B$. We obtain the following Lemma:

Lemma 2.1. Assume $\left(H_{2}\right)$. The basal area $B\left(\right.$.) satisfies $B(t) \leq B^{0}(t ; 1)$ for all $t \in[0, T]$.

Proof: From Eq. (1) we deduce: $\frac{d B(t)}{d t} \leq g(A B(t)) I(t)$ and $\frac{d B(t)}{g(A B(t))} \leq I(t) d t$. By integration between the initial time and time $t \leq t^{0}\left(\frac{1}{A}\right): \quad \int_{B_{0}}^{B(t)} \frac{d x}{g(A x)} \leq \int_{0}^{t} I(u) d u=\int_{B_{0}}^{B^{0}(t ; 1)} \frac{d x}{g(A x)} \quad$ which $\quad$ implies $\int_{B(t)}^{B^{0}(t ; 1)} \frac{d x}{g(A x)} \geq 0$. From the positivity of $g$ we deduce the result.

We are focusing here, on the setting in the timber market of a forest stand whose evolution is given the basal area Eq. (1) and tree-height $H$ (.). The timber incomes depend only on the basal area $B$ and the height $H$ : $p_{0} v(B, H)$ where $p_{0}$ is the timber price (net of thinning costs) and $v$ $(B, H)$ is the volume assumed to be proportional to the basal area $B$ and height $H: v(B, H)=c_{0} B H$.

\subsection{Optimal silviculture without natural risk}

Let $\delta$ the discount rate. We are assuming that a thinning of basal area $e(t)$ occurs at each time $t$ and the remaining trees would have been cut at age $T$. The criterion which we suggest to maximize is the sum of the thinning incomes per unit of time $x p_{0} c_{0} e(t) H(t)$ that would have occurred during the interval $[0, T]$ and the final income $x p_{0} c_{0} B(T) H(T)$ corresponding to the final cut at age $T$. The optimization problem, relating to the thinnings $e($.$) , on the interval [0, T]$, is therefore written:

$(\mathscr{P}): \max _{e(.) \in \mathscr{E}} W_{0}(T)=\int_{0}^{T} p_{0} c_{0} e(t) H(t) e^{-\delta t} d t+p_{0} c_{0} B(T) H(T) e^{-\delta T}$

where $\mathcal{E}=\{e() \mid. 0 \leq e(t) \leq \bar{e}$ for all $t\}$ and basal area $B$ following evolution given by Eq. (1) with initial conditions $B_{0}$ and fulfilling the constraint: $r(t)=A B(t) \leq 1$.

By replacing $e(t)$ by $g(A B(t)) I(t)-\frac{d B(t)}{d t}$, the optimization problem $(\mathscr{P})$ can be rewritten in terms of trajectory $B(t)$ :

$$
\begin{aligned}
\max _{B(.) \in \mathscr{C}_{B}} W_{0}(T)= & \int_{0}^{T} p_{0} c_{0}\left[g(A B(t)) I(t)-\frac{d B(t)}{d t}\right] H(t) e^{-\delta t} \\
& d t+p_{0} c_{0} B(T) H(T) e^{-\delta T}
\end{aligned}
$$

where $\mathscr{C}_{B_{0}}$ is the whole set of curves:

$$
\begin{aligned}
\mathscr{C}_{B_{0}} & =\left\{B(.) \in B C^{1}([0, T]) \mid B(0)\right. \\
& \left.=B_{0},-\bar{e}+g(A B(t)) I(t) \leq \frac{d B(t)}{d t} \leq g(A B(t)) I(t) \& A B(t) \leq 1\right\}
\end{aligned}
$$

where $B C^{1}$ stands for the space of bounded derivative functions defined on the interval $[0, T]$. By an integration by part we reformulate the program:

$\max _{B(.) \in \mathscr{C}_{B_{0}}} \int_{0}^{T} \mathscr{L}_{0}(B(t), t) e^{-\delta t} d t+p_{0} B_{0} H(0)$

where

$\mathscr{L}_{0}(B, t)=p_{0}\left[g(A B) I(t) H(t)-\delta B H(t)+B H^{\prime}(t)\right]$

The derivative of $\mathscr{L}_{0}(B, t)$ with respect to $B$ is proportional to:

$A g^{\prime}(A B) I(t) H(t)+H^{\prime}(t)-\delta H(t)$

Remark 2.1. In our study, due to the fact that the expression of the control variable can be substituted in the criterion, the control problem can be reduced to a calculus of variation problem. This substitution permits an easier study than the initial control problem. But it is not always possible and requires that the number of variables is not greater than the number of variables in the control.

On $B C^{1}$, the first order optimality condition given by the EulerLagrange Equation, applies (Blot and Cartigny, 1995). We suppose that 
$B($.$) stands for an interior solution and then B($.) has to satisfy: $\frac{\partial \mathcal{L}_{0}(B, t)}{\partial B}=0$ hence:

$A g^{\prime}(A B) I(t) H(t)=\delta H(t)-H^{\prime}(t)$

Let the function $\delta_{H}\left(\right.$.) defined by: $\delta_{H}(t)=\delta-\frac{H^{\prime}}{H}(t)$ for any $t>0$. Hence defines the time-dependent singular solution $\widehat{B_{1}}$ for $t \in[\underline{t}, \bar{t}]$ such that $A g^{\prime}(1) I(t) \leq \delta_{H}(t) \leq A g^{\prime}(0) I(t)$ and $\left.\left.A \widehat{B}_{1}(t) \in\right] 0,1\right]$ by: $A \widehat{B}_{1}(t)=g^{\prime-1}\left[\frac{\delta_{H}(t)}{A I(t)}\right]$. The corresponding singular control is: $\widehat{e}_{1}(t)=g\left(A \widehat{B}_{1}(t)\right) I(t)-\frac{d \widehat{B}_{1}(t)}{d t}$. For $t<\underline{t}$ (respectively $t>\bar{t}$ ) or for $B<\widehat{B}_{1}(t)$ (respectively $B>\widehat{B}_{1}(t)$ ) with $\underline{t}<t<\bar{t}$, $\frac{\partial \mathcal{L}_{0}(B, t)}{\partial B}$ is positive (respectively negative). We make the following assumptions:

$\left(H_{4}\right): A g^{\prime}(1) I(T)+\frac{H^{\prime}}{H}(T)<\delta<\lim _{t \rightarrow 0} \frac{H^{\prime}}{H}(t)$

With $\left(H_{3}\right)$ and this assumption $\delta_{H}(t)$ starts from a negative value at initial time, then increases and becomes sufficiently positive for large time value to ensure that the singular arc $\widehat{B}_{1}$ is not empty. Depending of the position of the cutting age $T$ with respect to $\underline{t}$ and position of $B\left(t_{0}\right)$ with respect to $\widehat{B}_{1}(\underline{t})$, the optimal solution differs. We assume $0<\underline{t}<T<\bar{t}, \hat{e}_{1}(t)<\bar{e}$ for $\underline{t}<t<T$ and $\left(H_{3}\right)$. Two cases may occur:

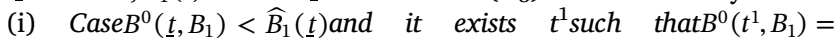
$\widehat{B}_{1}\left(t^{1}\right)$ with $\underline{t} \leq t^{1} \leq T$ :

Depending on the position of $\widehat{e}_{1}\left(t^{1}\right)$ with respect to $\bar{e}$ two subcases must be explored:

(ia) subcase $\widehat{e}_{1}\left(t^{1}\right) \leq \bar{e}$ :

Following the same reasoning that in (Sethi and Thompson, 2000), we deduce that the optimal solution $B_{0}{ }^{*}$ is characterized by:

$B_{0}^{*}(t)=\left\{\begin{array}{cc}B^{0}\left(t ; B_{1}\right) & \text { if } 0<t<t^{1} \\ \widehat{B}_{1}(t) & \text { if } t^{1} \leq t \leq T\end{array}\right.$

(ib) subcase $\widehat{e}_{1}\left(t^{1}\right)>\bar{e}$ :

Let $t_{r}>t^{1}>\bar{t}$ the time such that $\widehat{e}_{1}\left(t_{r}\right)=\bar{e}$. Starting from the curve $B^{0}\left(., B_{1}\right)$ the optimal solution reaches the singular arc. A transition trajectory between $B^{0}\left(., B_{1}\right)$ and the singular arc is needed. To show it, we noticed that the optimization problem on $[0, T]$ can be decomposed in two subproblems respectively on $\left[0, t_{r}\right]$ and on $\left[t_{r}, T\right]$. We deduce that the optimal trajectory is obtained by applying the maximum available control $e=\bar{e}$ at the end of the first period and reaches the singular arc at time $t_{r}$. Let $t_{l}$ the time which permits to reach the singular arc at time $t_{r}$ with the control $e=\bar{e}$ so the optimal trajectory is given by:

$B_{0}^{*}(t)=\widetilde{B}\left(t ; t_{l}\right)=\left\{\begin{array}{cc}B^{0}\left(t ; B_{1}\right) & \text { if } 0<t<t_{l} \\ \underline{B}\left(t ; t_{l}, B^{0}\left(t_{l} ; B_{1}\right)\right) & \text { if } t_{l} \leq t<t_{r} \\ \widehat{B}_{1}(t) & \text { if } t_{r} \leq t \leq T\end{array}\right.$

(ii) $\operatorname{Case}^{0}\left(\underline{t}, B_{1}\right)>\widehat{B_{1}}(\underline{t}), \operatorname{so} B^{0}\left(t, B_{1}\right)>\widehat{B_{1}}(t)$ for allt $>\underline{t}$ :

As in the previous case a transition trajectory between $B^{0}\left(., B_{1}\right)$ and the singular arc is needed. In this case we decomposed in two subproblems respectively on $[0, \underline{t}]$ and on $[\underline{t}, T]$ introducing a new control $B(t)$. Hence the optimal trajectory is obtained by applying the maximum available control $e=\bar{e}$ at the end of the first period and at the beginning of the second period. Let $\underline{t}_{l}^{1}$ the time which permits to reach the singular arc at time $\underline{t}$ with the control $e=\bar{e}$. The optimal trajectory is similar than in the previous case but with unknown switching time $t_{l}^{1}$ such that $\underline{t}_{l}^{1} \leq t_{l}^{1} \leq t$, to each $t_{l}^{1}$ it corresponds if it exists the time $t_{r}^{1}$ at which i.e. $\underline{B}\left(t_{r}^{1} ; t_{l}^{1}, B^{0}\left(t_{l}^{1} ; B_{1}\right)\right)=\widehat{B}_{1}\left(t_{r}^{1}\right)$, otherwise $t_{r}^{1}=T$. To each $t_{l}^{1}$ we associates the corresponding trajectory $\widetilde{B}\left(t ; t_{l}^{1}\right)$. The optimal switching time $t_{l}^{*}$ is given by: $t_{l}^{*}=\arg \max _{t_{l}^{1} \leq t_{l}^{1} \leq t} W_{\widetilde{B}\left(: t_{l}^{l}\right)}(T)$. We deduce the optimal trajectory: $B_{0}^{*}(t)=\widetilde{B}\left(t ; t_{l}^{*}\right)$.

\subsection{The natural risk case}

In case of natural risk, the chosen cutting age may not be reached. If a natural event occurs before a tipping age $t_{L}$, the event may have no impact due, for example if a storm occurs before a time $t_{L}$ due to the small tree-height the storm has no impact (Schmidt et al., 2010). Let $\tau$ the spending time between the beginning of the stand and the first event of the stand after $t_{L}$, either by destructive event or by logging at time $T$. The distribution of the time $\tau$ is: $F_{\tau}(t)=F$ $\left(t-t_{L}\right)=1-e^{-\lambda\left(t-t_{L}\right)}$ for $t_{L}<t \leq T$. We consider an adaptation of the scenario of (Reed, 1984) to the natural risk case taking into account the tipping age:

- if an event occurs at age $\tau \leq t_{L}$, the event has no impact, the stand continues to grow.

- if an event occurs at age $\tau$ with $t_{L}<\tau \leq T$, the proportion of damaged trees $\theta_{t}$ is non neglectable, a clearcutting and a regeneration of the stand is made at age $\tau$.

- if no event occurs before age $T$, a clearcutting and a regeneration of the stand is made at age $T$.

With this scenario, the real cutting age is random. In order to take it into account in the evaluation fo the silviculture it is suitable to use the Faustmann Approach. Let $\Delta=\delta+\lambda, \alpha(t)=E\left(1-\theta_{t}\right)$, we shows in Appendix $\mathrm{B}$ that, for fixed cutting $T$, maximizing the Faustmann value $J_{\lambda}$ is equivalent to maximize $W(T)$ which is a modified criterion of $W_{0}$ on $[0, T]$ taking into account the stochastic incomes due to natural risk:

$$
\begin{gathered}
\left(\mathscr{P}_{\lambda}\right): \max _{e(.) \in \mathscr{E}} W(T)=\int_{0}^{t_{L}} p_{0} c_{0} e(t) H(t) e^{-\delta t} d t \\
+\int_{t_{L}}^{T}\left[p_{0} e(t)+\lambda\left(\alpha(t) p_{0}-(1-\alpha(t)) c_{v}\right) B(t)\right] c_{0} H(t) e^{-\Delta t+\lambda t_{L}} d t \\
+p_{0} c_{0} B(T) H(T) e^{-\Delta T+\lambda t_{L}}
\end{gathered}
$$

Replacing $e(t)$ by $g(A B(t)) I(t)-\frac{d B(t)}{d t}$ and integrating by part we deduce that $\left(\mathscr{P}_{\lambda}\right)$ is equivalent to:

$\max _{B(.) \in \mathscr{C}_{B 0}} \int_{0}^{t_{L}} \mathscr{L}_{0}(B(t), t) e^{-\delta t} d t+\int_{t_{L}}^{T} \mathscr{L}_{\lambda}(B(t), t) e^{-\Delta t+\lambda t_{L}} d t+p_{0} B_{0} H(0)$

where: $\mathscr{L}_{\lambda}(B, t)=\mathscr{L}_{0}(B, t)-\lambda(1-\alpha(t))\left(p_{0}-c_{\nu}\right) B H(t)$.

As in the no-risk case, the control problem is reduced to a calculus of variation problem. The Euler Lagrange conditions give two singular Equations:

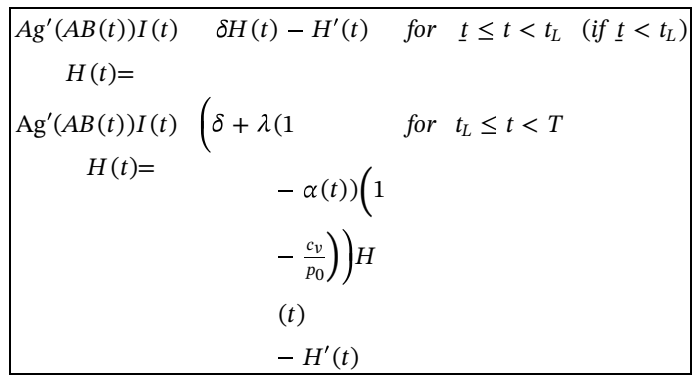

We deduce the existence for $t>t_{L}$ of a second singular arc $\widehat{B}_{2}$ defined for $t \in[\underline{t}, \overline{\bar{t}}]$ with similar condition than for the definition of $\underline{t}$ and $\bar{t}$. Assuming $c_{v}<p_{0}$, due the increasing of $\delta_{H}$, the decreasing of $I$ and the concavity of $g$ we deduce that $\underline{\underline{t}}<\underline{t}, \overline{\bar{t}}<\bar{t}$, this second singular arc is lower than the first singular arc and $\frac{\partial L_{\lambda}(B, t)}{\partial B}$ is positive for $t<\underline{\underline{t}}$ and for $B<\widehat{B}_{2}(t), \underline{\underline{t}}<t<\overline{\bar{t}}$. We assume $\underline{\underline{t}} \leq t_{L}$ and $T<\overline{\bar{t}}$. Depending on the position of threshold $t_{L}$ with respect to $t^{1}$ and the position of $B_{0}$ with respect to $\widehat{B}_{1}\left(t^{1}\right)$ or $\widehat{B}_{2}\left(t_{L}\right)$ the optimal solution differs: the optimal solution may not reach the first singular arc $\widehat{B}_{1}$ but reach the second singular arc $\widehat{B}_{2}$ or reach successively the first and the second singular.

If $t_{L} \leq t^{1}$, the optimal trajectory is obtained by replacing $\widehat{B_{1}}$ by $\widehat{B}_{2}$.

If $t_{L}>t^{1}$ and $\alpha\left(t_{L}\right)=1$, the optimal trajectory is obtained by replacing $\widehat{B}_{1}$ by $\widehat{B}_{12}$ which is defined by:

$\hat{B}_{12}(t)=\left\{\begin{array}{l}\hat{B}_{1}(t) \quad \text { if } \underline{t}<t<t_{L} \\ \hat{B}_{2}(t) \quad \text { if } t_{L}<t<T\end{array}\right.$

Otherwise, if $\alpha\left(t_{L}\right)<1$. As with no risk, two cases may occur: (i) $\operatorname{Case}^{0}\left(\underline{t}, B_{1}\right)<\widehat{B}_{1}(\underline{t})$ and it exists $t^{1}$ such that $B^{0}\left(t^{1}, B_{1}\right)=$ 
$\widehat{B_{1}}\left(t^{1}\right)$ with $\underline{t} \leq t^{1} \leq T$ :

(ia) subcase $\widehat{e}_{1}\left(t^{1}\right) \leq \bar{e}$ :

Following the same reasoning that with no risk, we let $\underline{t}_{l}^{2}$ the time which permits to reach the second singular arc at time $t_{L}$ with the control $e=\bar{e}$ i.e. $\widehat{B}_{2}\left(t_{L}\right)=\underline{B}\left(t_{L} ; \underline{t}_{l}^{2}, \widehat{B}_{1}\left(\underline{t}_{l}^{2}\right)\right)$. We assume $t^{1} \leq \underline{t}_{l}^{2}<t_{L}$. To each time $t_{l}^{2}$ such that $\underline{t}_{l}^{2} \leq t_{l}^{2} \leq t_{L}$, we correspond if it exists the time $t_{r}^{2}$ at which i.e. $\underline{B}\left(t_{r}^{2} ; t_{l}^{2}, \widehat{B}_{1}\left(t_{l}^{2}\right)\right)=\widehat{B}_{2}\left(t_{r}^{2}\right)$, otherwise $t_{r}^{2}=T$. For each $t_{l}^{2}$ we consider the trajectory $\widetilde{B}\left(. ; t_{l}^{2}\right)$ deduce the optimal trajectory based on the following trajectories:

$\widetilde{B}\left(t ; t_{l}^{2}\right)=\left\{\begin{array}{cc}B^{0}\left(t ; B_{1}\right) & \text { if } 0<t<t^{1} \\ \widehat{B}_{1}(t) & \text { if } t^{1}<t<t_{l}^{2} \\ \underline{B}\left(t ; t_{l}^{2}, \widehat{B}_{1}\left(t_{l}^{2}\right)\right) & \text { if } t_{l}^{2} \leq t \leq t_{r}^{2} \\ \left.\widehat{B}_{2}(t)\right) & \text { if } t_{r}^{2} \leq t \leq T\end{array}\right.$

The optimal switching time $t_{l}^{2 *}$ is given by: $t_{l}^{2 *}(T)=\arg \max _{\underline{t}_{l}^{2} \leq t_{l}^{2} \leq t_{L}} W_{\widetilde{B}_{\left(\cdot ; t_{l}^{2}\right)}}(T)$.

(ib) subcase $\widehat{e}_{1}\left(t^{1}\right)>\bar{e}$ :

Using the same reasoning than in the previous we consider the trajectories $\widetilde{B}\left(t ; t_{l}^{1}, t_{l}^{2}\right)$ for each $t_{l}^{2} \geq \underline{t}_{l}^{2}$ (assumed $\geq t_{r}$ ) with corresponding $t_{r}^{2}$ :

$\widetilde{B}\left(t ; t_{l}, t_{l}^{2}\right)=\left\{\begin{array}{cc}B^{0}\left(t ; B_{1}\right) & \text { if } 0<t<t_{l} \\ \underline{B}\left(t ; t_{l}, B^{0}\left(t_{l} ; B_{1}\right)\right. & \text { if } t_{l} \leq t \leq t_{r} \\ \widehat{B_{1}}(t) & \text { if } t_{r} \leq t \leq t_{l}^{2} \\ \underline{B}\left(t ; t_{l}^{2}, \widehat{B}_{1}\left(t_{l}^{2}\right)\right) & \text { if } t_{l}^{2} \leq t \leq t_{r}^{2} \\ \left.\widehat{B_{2}}(t)\right) & \text { if } t_{r}^{2} \leq t \leq T\end{array}\right.$

The optimal switching times $t_{l}^{2 *}$ is given by: $t_{l}^{2 *}=\arg \max _{t_{-}^{2} \leq t_{l}^{2} \leq t_{L}} W_{\left.\widetilde{B}_{(\cdot ; l,}, t_{l}^{2}\right)}(T)$.

(ii) $\operatorname{Case}^{0}\left(\underline{t}, B_{1}\right)>\widehat{B}_{1}(\underline{t}), \operatorname{so} B^{0}\left(t, B_{1}\right)>\widehat{B}_{1}(t)$ for allt $>\underline{t}$ :

We consider the trajectories $\widetilde{B}\left(t ; t_{l}^{1}, t_{l}^{2}\right)$ for each $t_{l}{ }^{1}, t_{l}{ }^{2}$ with corresponding $t_{r}^{1}, t_{r}^{2}$ and assume $t_{r}^{1} \leq \underline{t}_{l}^{2} \leq t_{l}^{2}$. The optimal switching times

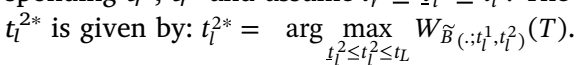

Hence more generally, due the fact that the second singular arc is lower than the first singular arc, cuttings are the same or are made earlier in the case with risk. It is a self insurance strategy used by the forest manager.

\subsection{Numerical application}

We propose a numerical application to help visualize the main findings or implications of the previous results. For this numerical simulation, we consider a beech forest at the stand level. Table 1 presents the function values used to solve the problem in the benchmark case.

To complete: $T=100$ year, $t_{L}=61$ year, $\delta=0.02$ year $^{-1}$, $\lambda=0.015$ year $^{-1}$.

We deduce the expressions of $B^{0}\left(t, B_{1}\right), \widehat{B_{1}}$ and $\widehat{B}_{2}$ :

Table 1

selected functions and parameters.

\begin{tabular}{lll}
\hline & Function & Parameters \\
\hline RdI & $A B \leq 1$ & $\begin{array}{l}A=3 / 160 \mathrm{~m}^{-2} \text { (i.e. } \\
\left.B_{1}=53.33 \mathrm{~m}^{2}\right)\end{array}$ \\
Height & $H(t)=H_{0} \cdot\left(1-e^{-p_{4} \cdot t}\right)$ & $\begin{array}{l}H_{0}=40 \mathrm{~m}, \\
p_{4}=0.0121 \text { year }^{-1}\end{array}$ \\
& $H^{\prime}(t)=p_{4} \cdot H_{0} \cdot e^{-p_{4} \cdot t}$ & \\
Increase & $I(t)=p_{2}+p_{3} \cdot H^{\prime}(t)$ & $p_{2}=0.15 \mathrm{~m}^{2} \mathrm{year}^{-1}$, \\
& & $p_{3}=2.056 \mathrm{~m}^{-2}$ \\
Density-dependence & $g(B)=1-e^{-p_{1} . B}$ & $p_{1}=0.4158 \mathrm{~m}^{-2}$ \\
Salvage proportion & $\alpha(t)=\left[p_{5}+\left(t-t_{L}\right)\right.$. & $p_{5}=0.2, p_{6}=0.01$ year $^{-1}$ \\
& $\left.p_{6}\right] I_{t}>t_{L}$ &
\end{tabular}

$$
\begin{gathered}
B^{0}\left(t, B_{1}\right)=\left\{\begin{array}{cc}
\frac{1}{p_{1}} \log \left(1+e^{p_{1} \cdot\left(p_{2} \cdot t+p_{3} \cdot H(t)\right)} \cdot\left(e^{p_{1} \cdot B_{0}}-1\right)\right) & \text { for } t<t^{0}, \\
B_{1} & \text { for } t>t^{0}
\end{array}\right. \\
\widehat{B}_{1}(t)=-\frac{1}{p_{1}} \log \left(\frac{1}{p_{1} I(t)}\left(\delta-\frac{H^{\prime}(t)}{H(t)}\right)\right) \\
\widehat{B}_{2}(t)=-\frac{1}{p_{1}} \log \left(\frac{1}{p_{1} I(t)}\left(\delta+\lambda(1-\alpha(t))\left(1-\frac{c_{v}}{p_{0}}\right)-\frac{H^{\prime}(t)}{H(t)}\right)\right)
\end{gathered}
$$

Hence, $\underline{t}=32.625$ years, $B^{0}\left(\underline{t}, B_{1}\right)=11.82 \mathrm{~m}^{2}$ and $\widehat{B_{1}}(\underline{t})=29.45 \mathrm{~m}^{2}$ so we are in the case (i). Moreover $t^{1}=34.125$ years and $\hat{e}_{1}\left(t^{1}\right)=2.19 m^{2}$ year $^{-1}$. Depending on whether $\widehat{e}_{1}\left(t^{1}\right)$ is smaller or larger than $\bar{e}$ the optimal trajectory differs. Thus if $\bar{e}=2.2 m^{2} y e a r^{-1}$ the optimal trajectory is of type (ia) and given in Fig. 1 for the no-risk case and Fig. 2 for the risk case. At the opposite if $\bar{e}=1.25 \mathrm{~m}^{2}$ year $^{-1}$ the optimal trajectory is of type (ib) with $t_{l}=33.45$ years et $t_{r}=38$ years and given in Fig. 3 for the no-risk case and Fig. 4 for the risk case.

\subsection{Impact of natural risk on optimal cutting age}

Now, we consider the optimization of the Faustmann Value with respect to the cutting age with the previous optimal silviculture.

Proposition 2.1. For sufficiently low risk rate $\lambda$, if $\int t_{t_{L}}{ }^{T}[R(B(T), T)-R$ $\left.(B(t), t)+\left(t-t_{L}\right)\left(\mathscr{L}_{0}(B(T), T)-\mathscr{L}_{0}(B(t), t)\right)\right] e^{-\delta t} d t>0$ (with $R$ $\left.(B, t)=\left(p_{0}-c_{v}\right)(1-\alpha(t)) B H(t)\right)$ then the optimal cutting age with risk is shorter than optimal cutting age without risk.

The proof is given in Appendix C. For sufficiently decreasing expected proportion survival tree $\alpha$ and not too high value of $T-t_{L}$, the condition in Proposition 2.1 is satisfied and the optimal cutting age $T$ is shortened in case of risk. This conclusion is in accordance with the empirical results of the literature.

\section{The optimization problem based on sequestered carbon}

We assume that there exists a carbon market, hence increasing (resp. decreasing) of sequestered carbon is valuated positively (resp. negatively).

\subsection{Without natural risk}

Denote the individual sequestered carbon $c(B, H)=k B H$ for a basal area $B$ and tree height $H$ where $k$ is a conversion coefficient in $t \mathrm{CO}_{2} \mathrm{~m}^{-3}$. The exported wood is divided in wood energy and timber with the corresponding proportion $x_{E}$ and $x_{T}$. The respective carbon flux can be specified.

Inside the forest:

- in the vegetation:

$$
\begin{aligned}
F_{V}= & k \int_{0}^{T} \frac{d B(t) H(t)}{d t} e^{-\delta t} d t-k B(T) H(T) e^{-\delta T} \\
= & k \int_{0}^{T}\left[g(A B(t)) I(t) H(t)+B(t) H^{\prime}(T)\right] e^{-\delta t} d t \\
& -k\left(\int_{0}^{T} e(t) H(t) e^{-\delta t} d t+B(T) H(T) e^{-\delta T}\right)
\end{aligned}
$$

\section{Outside the forest:}

- in the wood products from the exported trees:

$$
F_{W}=\frac{\delta k}{\gamma_{p}+\delta} x_{T}\left(\int_{0}^{T} e(t) H(t) e^{-\delta t} d t+B(T) H(T) e^{-\delta T}\right)
$$




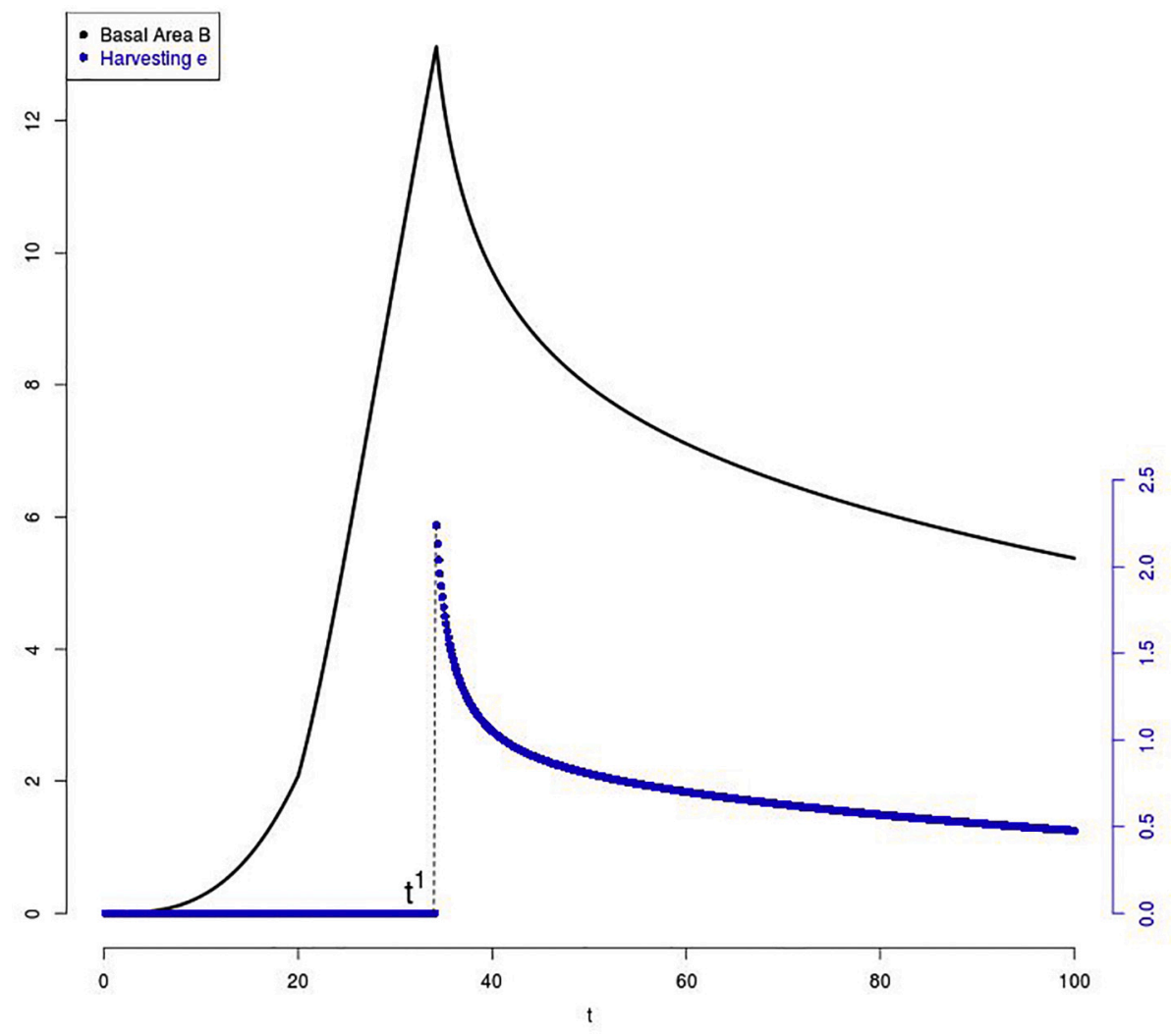

Fig. 1. Optimal Basal Area without risk and associated optimal harvesting in case (ia).

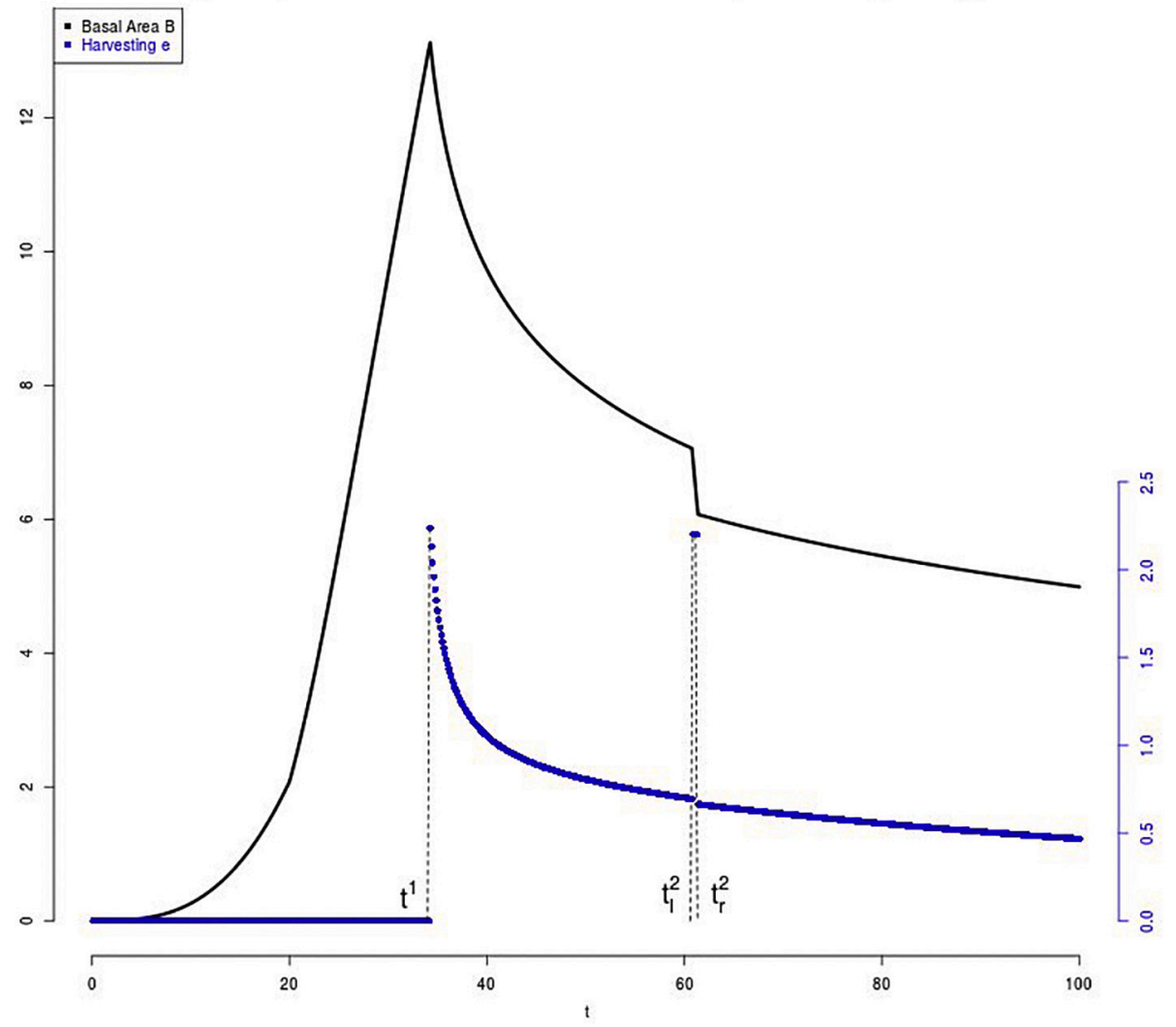

Fig. 2. Optimal Basal Area with natural risk and associated optimal harvesting in case (la). 


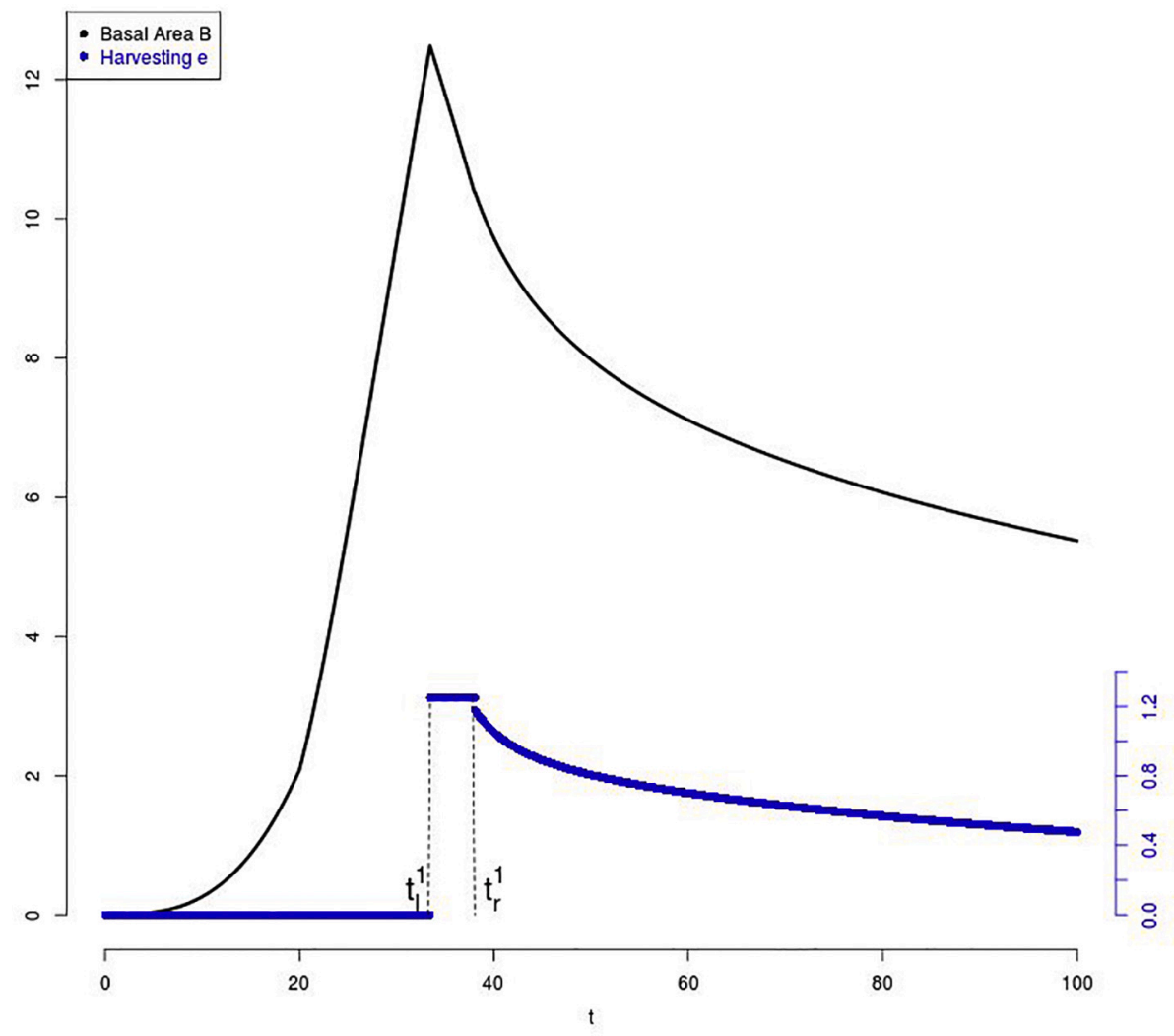

Fig. 3. Optimal Basal Area without risk and associated optimal harvesting in case (ib).

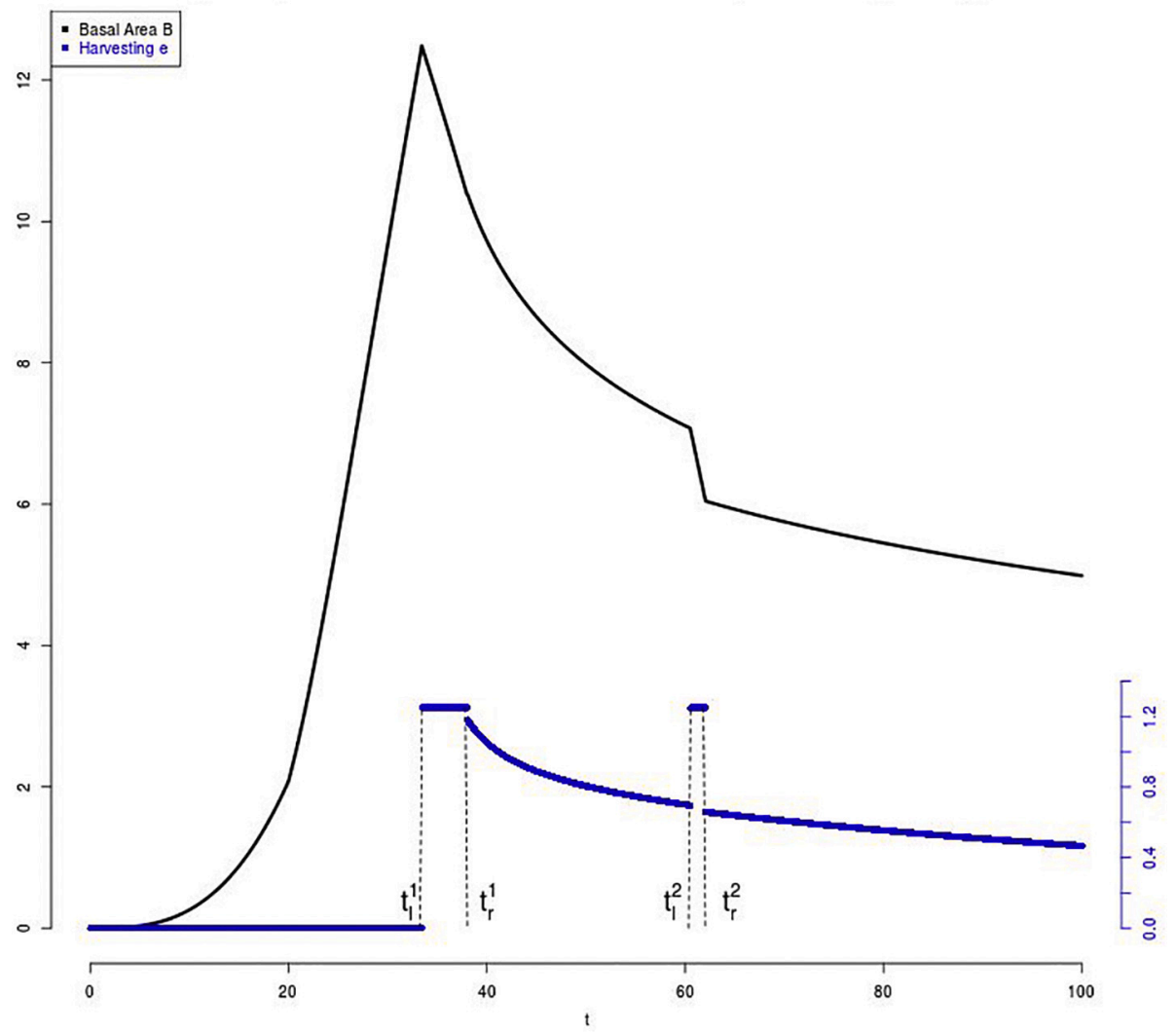

Fig. 4. Optimal Basal Area with natural risk and associated optimal harvesting in case (lb). 
where $\gamma_{p}$ is the discount carbon rate in energy.

- in energy from the exported trees: we assume that in the end all the exported trees ends in energy. Proportion $x_{E}$ is converted directly in wood energy and proportion $x_{T}$ is converted with discount carbon rate $\left.\gamma_{p}\right)$ :

$F_{E}=C_{E}\left(x_{E}+\frac{\gamma_{p}}{\gamma_{p}+\delta} x_{T}\right)\left(\int_{0}^{T} e(t) H(t) e^{-\delta t} d t+B(T) H(T) e^{-\delta T}\right)$

where $C_{E}$ is the substitutability coefficient, $C_{E}<k$.

We may decide to choose to consider:

(i) only the carbon flux corresponding to the vegetation $F_{V}$, by convention $\gamma_{V}=+\infty$.

(ii) the carbon flux corresponding to the vegetation and the wood products $F_{V}+F_{W}$, hence we let $\gamma_{V W}$ such that $\frac{\delta}{\gamma_{V W}+\delta}=\frac{\delta}{\gamma_{p}+\delta} x_{T}$.

(iii) the previous fluxes and the flux corresponding the substitutable energy then consider $F_{V}+F_{W}+F_{E}$, hence we let $\gamma_{V W E}$ such that $\frac{\delta}{\gamma_{V W E}+\delta}=\frac{\delta}{\gamma_{p}+\delta} x_{T}+\frac{C_{E}}{k}\left(x_{E}+\frac{\gamma_{p}}{\gamma_{p}+\delta} x_{T}\right)$ (with $\frac{C_{E}}{k} \leq 1$ ).

Remark: The different products have different carbon discount rates but in this case it is enough in this case to calculate an average carbon discount rate as we did to build $\gamma_{V W E}$. The only outstanding problem is the variable composition over time but this has only a very marginal impact on the final result.

We have the following relations: $\gamma_{V W E}<\gamma_{V W}<\gamma_{V}=+\infty$. In all cases, the criterion to optimize can be expressed in the following form:

(2):

$$
\begin{array}{rl}
\max _{e(.) \in \mathscr{E}} & k \int_{0}^{T}\left[g(A B(t)) I(t) H(t)+B(t) H^{\prime}(t)\right] e^{-\delta t} d t \\
& -\frac{\gamma}{\gamma+\delta} k\left(\int_{0}^{T} e(t) H(t) e^{-\delta t} d t+B(T) H(T) e^{-\delta T}\right)
\end{array}
$$

with the corresponding $\gamma$.

Hence by replacing $e(t)$ by $g(A B(t)) I(t)-\frac{d B(t)}{d t}$ and integrating by parts, we deduce that problem $(\mathscr{Q})$ is equivalent to:

$\max _{B(.) \in \mathscr{\mathscr { C }}_{B_{0}}} \int_{0}^{T} \mathscr{L}_{0}^{C}(B(t), t) e^{-\delta t} d t-\frac{\gamma}{\gamma+\delta} k B_{0} H(0)$

with $\mathcal{L}_{0}^{C}(B, t)=\frac{\delta k}{\gamma+\delta}\left(g(A B) I(t) H(t)+B H^{\prime}(t)+\gamma B H(t)\right)$. The derivative of $\mathscr{L}_{0}{ }^{C}(B, t)$ with respect to $B$ is proportional to:

$A g^{\prime}(A B) I(t) H(t)+H^{\prime}(t)+\gamma H(t)$

is positive for all time $t$. Hence the optimal trajectory is the trajectory which gives the higher value of basal area i.e. $B^{0}(. ; 1)$.

\subsection{Comparison with optimization based on timber production}

The optimal trajectory for the carbon sequestration consists in keeping standing timber as long as possible. Therefore optimal solution for the carbon sequestration is slightly different with the optimal solution for timber criterion $B_{0}{ }^{*}$.

\subsection{The natural risk case}

In case of natural risk, we assume that the damaged trees have a higher discount carbon rate $\Gamma$. With the same reasoning that for the timber criterion (see Appendix D) we obtain a Faustmann criterion proportional to:

$$
=\int_{0}^{t_{L}} \mathscr{L}_{0}^{C}(B(t), t) e^{-\delta t} d t+\int_{t_{L}}^{T} \mathscr{L}_{\lambda}^{C}(B(t), t) e^{-\Delta t+\lambda t_{L}} d t
$$

where

$$
\mathscr{L}_{\lambda}^{C}(B, t)=\mathscr{L}_{0}^{C}(B, t)-\lambda \frac{\delta}{\gamma+\delta} k \frac{\Gamma-\gamma}{\Gamma+\delta}(1-\alpha(t)) B H(t)
$$

The derivative of the integrand with respect to $B$ is proportional to:

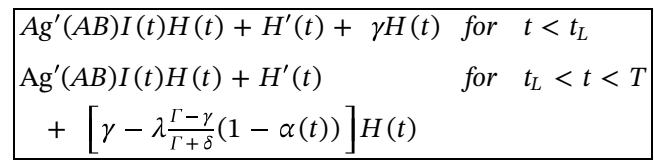

Remark 3.1. As $\delta \ll \Gamma$, the first order condition weakly depends on the economic discount rate $\delta$.

We deduce:

i) For $t<t_{L}$ and if $\lambda<\gamma \frac{\Gamma+\delta}{\Gamma-\gamma}$ for $t>t_{L}$, there is no singular arc. Hence, first there is no thinning before the tipping age $t_{L}$. Second, if $\lambda$ is lower than $\gamma$ so in this case the optimal trajectory will be the same than in the no risk case: no thinning.

ii) For sufficiently high value of the risk rate $\lambda, \gamma-\lambda \frac{\Gamma-\gamma}{\Gamma+\delta}(1-\alpha(t))$ would be negative and a singular arc exists.

\subsection{Comparison with optimization based on timber production}

Except for very high (and therefore usually unrealistic) risk rate values, the optimal trajectory for carbon sequestration is identical to that without risk and therefore very different from that obtained for the timber criterion. With risk but sufficiently high risk rate, the optimal trajectory for carbon sequestration is a little closer to the optimal trajectory for timber production.

\subsection{Optimal cutting age}

without risk.

We consider the optimization of the Faustmann Value with respect to the cutting age with the previous optimal silviculture, the Faustmann Value is:

$J_{0}^{C}=\frac{\int_{0}^{T} L_{0}^{C}(t) e^{\delta(T-t)} d t}{e^{\delta T}-1}$

with $L_{0}{ }^{C}(t)=\mathscr{L}_{0}{ }^{C}\left(B^{0}(t ; 1), t\right)$. We deduce:

Lemma 3.1. If $L_{0}{ }^{C}$ satisfies: $\int_{0}{ }^{T}\left(L_{0}{ }^{C}(T)-L_{0}{ }^{C}(t)\right) e^{-\delta t} d t>0$ for all $T$, then the Faustmann Value $J_{0}{ }^{C}$ is increasing with respect to cutting age $T$. Therefore the optimal cutting age will be the senescence age.

Proof: The derivative of $J_{0}{ }^{C}$ with respect to $T$ is proportional (with the same sign) to:

$$
\begin{gathered}
L_{0}^{C}(T)\left(e^{\delta T}-1\right)-\delta \int_{0}^{T} L_{0}^{C}(t) e^{\delta(T-t)} d t \\
\quad=\delta \int_{0}^{T}\left(L_{0}^{C}(T)-L_{0}^{C}(t)\right) e^{\delta(T-t)} d t
\end{gathered}
$$

Due to non neglectable value of $\gamma, L_{0}{ }^{C}(t)$ will be increasing hence will satisfy the condition in Lemma 3.1. We note that the condition expressed in Lemma 3.1 authorizes a weak decreasing for old ages.

with natural risk.

For $\lambda<\gamma \frac{\Gamma+\delta}{\Gamma-\gamma}$, there is no singular arc hence the Faustmann Value is given by:

$J_{0}^{C}=\frac{\left(\int_{0}^{t_{L}} L_{0}^{C}(t) e^{-\delta t} d t+\int_{t_{L}}^{T} L_{\lambda}^{C}(t) e^{-\Delta t+\lambda t_{L}} d t\right) e^{\Delta T-\lambda t_{L}}}{b(T)}$

with $\left.L_{\lambda}{ }^{C}(t)=\mathscr{L}_{\lambda}{ }^{C}\left(B^{0}(t ; 1), t\right)\right)$. We deduce:

Lemma 3.2. If $L_{0}{ }^{C}, \quad L_{\lambda}{ }^{C}$ satisfy: $\int_{0}{ }_{0}{ }^{t_{L}}\left(L_{\lambda}{ }^{C}(T)-L_{0}{ }^{C}(t)\right)$ $e^{-\delta t} d t+\int t_{t_{L}}{ }^{T}\left(L_{\lambda}{ }^{C}(T)-L_{\lambda}{ }^{C}(t)\right) e^{-\Delta t+\lambda t_{L}} d t>0$ for all $T$, then the Faustmann Value $J_{0}{ }^{C}$ is increasing with respect to cutting age $T$. Therefore the optimal cutting age will be the senescence age.

Hence for moderate value of $\lambda$, the optimal cutting age will be the senescence age as in the no risk case.

At the opposite, for sufficiently high value $\lambda$ and moderate discount 
carbon rate $\gamma, \gamma-\lambda$ may be negative so $L_{\lambda}{ }^{C}$ may not satisfy the condition of the Lemma 3.2 hence the optimal cutting age may be lower than the senescence age: if $\lambda(1-\alpha(t))>\gamma$ a singular arc is available and as in the classical Faustmann problem an optimal cutting age may exist.

\subsection{Comparison with optimization based on timber production}

Except for very high (and therefore usually unrealistic) risk rate values, the optimal cutting age for carbon sequestration with or without risk will be the senescence age and therefore very different from the optimal cutting age for the timber criterion. With risk but sufficiently high risk rate, the optimal cutting age for sequestered carbon may not be deduced from the senescence age and is a little closer to optimal timber cutting age.

\section{Discussion}

The work presented here has focused on timber revenues and carbon sequestration separately. As such, it differs from work in the literature that focused on joint production. In contrast to the latter, our study provides a precise analysis of strategies to improve carbon sequestration in forests.

In our study, due to the fact that the expression of the control variable can be substituted in the criterion, the control problem can be reduced to a Calculus of Variations problem. This substitution permits an easier study than the initial control problem. Calculus of Variations works fine for our problem but it may not be as useful for other optimal rotation problems.

The results presented have been obtained by making simplifying assumptions, which allowed us to determine the optimal strategies. These simplifications concerned the price function, the diversity of carbon discount rates and as we have expressed are justified as they have no serious consequences.
An important point concerns the consideration of changing environmental conditions. In the Faustmann approach, it is assumed that the environmental conditions are the same to each new rotation. To take into account changing environmental conditions, it becomes necessary to work with a value function.

\section{Conclusion}

From analytical expression of the criteria to optimize, we compare optimal strategies (in term of thinning and cutting age) that maximize carbon sequestration to optimal strategies that maximize the timber income. The study presented is done at the stand level. We show that the optimal trajectory for the carbon sequestration consists in keeping standing timber as long as possible. Therefore optimal solution for the carbon sequestration is slightly different with the optimal solution for timber criterion. With no natural risk or with risk but low risk rate, the optimal cutting age for sequestered carbon will be the senescence age. With natural risk but sufficiently high risk rate, the optimal trajectory for carbon sequestration is a little closer to the optimal trajectory for timber production.

To extend this study, we could consider risk averse forest managers, which should substantially modify the optimal strategies for carbon sequestration. Moreover to take into account changing environmental conditions, we could consider a function value approach.

\section{Author statement}

The authors state that no experimentation with human subject has been done.

\section{Declaration of Competing Interest}

None.

\section{Appendix A. The growth model}

We consider a forest stand. The tree number which this area can bear is limited. Let's note $b$ the average tree basal area (at the height of 1.3 meters) of the forest, the maximum tree number $n_{M}(b)$ that a forest stand can bear is given by the self-thinning relation (Reineke, 1933): $\log n_{M}(b)=C_{0}-\frac{q}{2} \log b, C_{0}>0,1<q \leq 2$ are constant values characteristic of the forest species and of its environment (ground fertility). Hence, for a given averaged tree basal area $b$, beyond the tree number $n_{M}(b)$, the trees die, the forest stand has to remain under this limit. Reineke (Reineke, 1933) defines the Relative Density Index $R D I$ by: $r=\frac{n}{n_{M}(b)}=A n b^{\frac{q}{2}}$ with $A:=e^{-C_{0}}$. By definition this ratio is always less than 1 . We will now describe the temporal evolution of the total basal area $B=n b$.

The growth of the trees depends on the tree density $r$ : the increase of basal area of the forest stand at its peak of density $r=1$ is given by the function $I(t)$ at time $t$ (Loisel and Dhôte, 2011). For a lower density $(r<1)$, the increase of the basal area for the forest is reduced by a factor dependent on this same density: $g(r)$. Thus the effective increase at time $t$ is equal to: $g(r(t)) I(t)$ hence, for a cutting policy $e($.$) , the evolution of the$ basal area is given by:

$\frac{d n(t) b(t)}{d t}=g(r(t)) I(t)-e(t)$

with the initial basal area $B_{0}=n_{0} b_{0}$, the constraints $0 \leq e(t) \leq \bar{e}$ and $r(t)=A n(t) b^{\frac{q}{2}} \leq 1$ for any $t$. A complete analysis of this model is given in (Loisel and Dhôte, 2011). We here consider the limit case $q=2$. In this case, the $R D I$ is proportional to the total basal area: $B=n b$ and $r=A B$.

\section{Appendix B. Timber production with risk}

Let $\tau_{i}$ the time spent between the beginning of the stand and the first event of the stand after $t_{L}$, either by event or by logging at time $T$ for the $i$ th rotation. The net economic return $\mathscr{Y}_{i}$ (thinning incomes, final income minus costs) actualized at final time $\tau$ is given by:

$\mathscr{Y}_{i}=\left\{\begin{array}{cl}p_{0} c_{0}\left(\int_{0}^{\tau_{i}} e(t) H(t) e^{\delta\left(\tau_{i}-t\right)} d t+\left(1-\theta_{\tau}\right) B\left(\tau_{i}\right) H\left(\tau_{i}\right)\right)-c_{1}-\theta_{\tau} c_{v} c_{0} B\left(\tau_{i}\right) H\left(\tau_{i}\right) & \text { if } t_{L}<\tau_{i}<T \\ p_{0} c_{0}\left(\int_{0}^{T} e(t) H(t) e^{\delta(T-t)} d t+B(T) H(T)\right)-c_{1} & \text { if } \tau_{i}=T\end{array}\right.$ 
with costs $c_{v}$ per unit of volume of damaged trees.

As the event occurs independently of one another and randomly in time, we deduce the following expression for the Faustmann Value:

$J_{\lambda}=E\left[\sum_{i=1}^{\infty} e^{-\delta\left(\tau_{1}+\tau_{2}+\ldots+\tau_{i}\right)} \mathscr{Y}_{i}\right]=E\left[e^{-\delta \tau_{1}}\left(\mathscr{Y}_{1}+\sum_{i=1}^{\infty} e^{-\delta\left(\tau_{2}+\ldots+\tau_{i}\right)} \mathscr{Y}_{i}\right)\right]=E\left[e^{-\delta \tau}\left(\mathscr{Y}+J_{\lambda}\right)\right]$

Hence, the Faustmann Value is the expected value of the actualized sum at the initial time of the net economic return $\mathscr{Y}$ and the Faustmann Value. Moreover the Fautmann value is given by:

$J_{\lambda}=\frac{E\left[e^{-\delta \tau} \mathscr{Y}\right]}{1-E\left[e^{-\delta \tau}\right]}$

From $E\left[e^{-\delta \tau} \mathscr{Y}\right]=\int_{t_{L}}^{T} e^{-\delta \tau} \mathscr{Y}(\tau) d F\left(\tau-t_{l}\right)+e^{-\delta T} \mathscr{Y}(T)\left(1-F\left(T-t_{L}\right)\right)$, inverting the integral with respect to $\tau$ and $t$ we deduce:

$J_{\lambda}=\frac{W(T) c_{0} e^{\Delta T-\lambda t_{L}}-c_{1} a(T)}{b(T)}$

with $W(T)=$

$\int_{0}^{t_{L}} p_{0} e(t) H(t) e^{-\delta t} d t$

$+\int_{t_{L}}^{T}\left[x p_{0} e(t)+\lambda\left(\alpha(t) p_{0}-(1-\alpha(t)) c_{v}\right) B(t)\right] H(t) e^{-\Delta t+\lambda t_{L}} d t$

$+p_{0} B(T) H(T) e^{-\Delta T+\lambda t_{L}}$

and constants $a(T), b(T): \Delta a(T)=\lambda e^{\Delta\left(T-t_{L}\right)}+\delta$ and $b(T)=e^{\Delta T-\lambda t_{L}}-a(T)$.

Appendix C. Proof of Proposition 2.1

From expression of: $W=\int_{0}{ }^{t_{L}} \mathscr{L}_{0}(B(t), t) e^{-\delta t} d t+\int_{t_{L}}{ }^{T} \mathscr{L}_{\lambda}(B(t), t) e^{-\Delta t+\lambda t_{L}} d t$ we deduce:

$$
W_{T}=\mathscr{L}_{\lambda}(B(T), T) e^{-\Delta T+\lambda t_{L}}
$$

$W_{T \lambda}=-\left(T-t_{L}\right) W_{T}+R(B(T), T) e^{-\Delta T+\lambda t_{L}}$

$W_{\lambda}=-\int_{t_{L}}^{T}\left[R(B(t), t)+\left(t-t_{L}\right) \mathscr{L}_{\lambda}(B(t), t)\right] e^{-\Delta t+\lambda t_{L}} d t$

In this case:

$$
\begin{gathered}
A(T)=\left[\left(b_{\lambda}-\left(T-t_{L}\right) b\right) W_{T}-b R(B(T), T) e^{-\delta T}-\delta W_{\lambda}\right]_{\mid \lambda=0} \\
=\left(T-t_{L}-\frac{e^{\delta\left(T-t_{L}\right)}-1}{\delta}\right) \mathscr{L}_{0}(B(T), T) e^{-\delta T}-R(B(T), T)\left(1-e^{-\delta T}\right) \\
+\delta \int_{t_{L}}^{T}\left[R(B(t), t)+\left(t-t_{L}\right) \mathscr{L}_{0}(B(t), t)\right] e^{-\delta t} d t \\
=\delta \int_{t_{L}}^{T}\left[R(B(t), t)-R(B(T), T)+\left(t-t_{L}\right)\left(\mathscr{L}_{0}(B(t), t)-\mathscr{L}_{0}(B(T), T)\right)\right] e^{-\delta t} d t<0
\end{gathered}
$$

\section{Appendix D. Carbon sequestration with risk}

The net carbon return $\mathscr{Y}_{i}^{C}$ actualized at final time $\tau$ is given by:

$$
\mathscr{Y}_{i}^{C}=\left\{\begin{array}{cc}
\int_{0}^{\tau_{i}} k\left[g(A B(t)) I(t) H(t)+B(t) H^{\prime}(t)\right] e^{\delta\left(\tau_{i}-t\right)} d t & \\
-\frac{\gamma}{\gamma+\delta}\left(\int_{0}^{\tau_{i}} k e(t) H(t) e^{\delta\left(\tau_{i}-t\right)} d t+\left(1-\theta_{\tau}\right) k B\left(\tau_{i}\right) H\left(\tau_{i}\right)\right) & \\
-\frac{\Gamma}{\Gamma+\delta} k \theta_{\tau} B\left(\tau_{i}\right) H\left(\tau_{i}\right) & \text { if } t_{L}<\tau_{i}<T \\
\int_{0}^{T} k\left[g(A B(t)) I(t) H(t)+B(t) H^{\prime}(t)\right] e^{\delta\left(\tau_{i}-t\right)} d t & \\
-\frac{\gamma}{\gamma+\delta}\left(\int_{0}^{T} k e(t) B(t) H(t) e^{\delta(T-t)} d t+k B(T) H(T)\right) & \text { if } \tau_{i}=T
\end{array}\right.
$$

Similarly for the timber case, we deduce the criterion:

$J_{\lambda}^{C}=\frac{W^{C}(T) e^{\Delta T-\lambda t_{L}}}{b(T)}$

with:

$W^{C}(T)=$

$$
\begin{gathered}
\int_{0}^{t_{L}} k\left[g(A B(t)) I(t) H(t)+B(t) H^{\prime}(t)\right] e^{-\delta t} d t \\
+\int_{t_{L}}^{T} k\left[g(A B(t)) I(t) H(t)+B(t) H^{\prime}(t)\right] e^{-\Delta t+\lambda t_{L}} d t \\
-\frac{\gamma}{\gamma+\delta} k \int_{0}^{t_{L}} e(t) H(t) e^{-\delta t} d t \\
-\frac{\gamma}{\gamma+\delta} k\left(\int_{t_{L}}^{T}[e(t) H(t)+\lambda \alpha(t) B(t) H(t)] e^{-\Delta t+\lambda t_{L}} d t+B(T) H(T) e^{-\Delta T+\lambda t_{L}}\right) \\
-\frac{\Gamma}{\Gamma+\delta} k \int_{t_{L}}^{T} \lambda(1-\alpha(t)) B(t) H(t) e^{-\Delta t+\lambda t_{L}} d t
\end{gathered}
$$


Hence by replacing $e(t)$ by $g(A B(t)) I(t)-\frac{d B(t)}{d t}$ and integrating by parts we obtain:

$W^{C}(t)=\int_{0}^{t_{L}} \mathscr{L}_{0}^{C}(B(t), t) e^{-\delta t} d t+\int_{t_{L}}^{T}\left(\mathscr{L}_{0}^{C}(B(t), t)-\lambda k \frac{\delta}{\gamma+\delta} \frac{\Gamma-\gamma}{\Gamma+\delta}(1-\alpha(t)) B(t) H(t)\right) e^{-\Delta t+\lambda t_{L}} d t+\frac{\gamma}{\gamma+\delta} k B(0) H(0)$

\section{References}

Assmuth, A., Tahvonen, O., 2018. Optimal carbon storage in even- and uneven-aged forestry. Forest Policy Econ. 87, 93-100.

Blot, J., Cartigny, P., 1995. Bounded solutions and oscillations of concave lagrangian systems in presence of a discount rate. Zeitschrift fur Analysis und ihre Andwendungen 14 (4), 731-750.

Clark, C., 1976. Mathematical Bioeconomics. Wiley, New York.

Creedy, J., Wurzbacher, A.D., 2001. The economic value of a forested catchment with timber, water and carbon sequestration benefits. Ecol. Econ. 38 (1), 71-83.

Deegen, P., Matolepszy, K., 2015. Economic balancing of forest management under storm risk, the case of the Ore Mountains (Germany). J. For. Econ. 21 (1), 1-13.

Faustmann, M., 1849. Berechnung des Wertes, welchen Waldboden sowie noch nicht haubare Holzbestände für die Waldwirtschaft besitzen. Allgemeine Forst-und JagdZeitung 25, 441-445.

Gutrich, J., Howarth, R.B., 2007. Carbon sequestration and the optimal management of New Hampshire timber stands. Ecol. Econ. 62 (3-4), 441-450.

Haight, R.G., Monserud, R.A., Chew, J.D., 1992. Optimal harvesting with stand density targets: managing rocky mountain conifer stands for multiple forest outputs. For. Sci. 38 (3), 554-574.

Hartman, R., 1976. The harvesting decision when a standing forest has value. Econ. Inq. 14 (1), 52-58.

Kaipainen, T., Liski, J., Pussinen, A., Karjalainen, T., 2004. Managing carbon sinks by changing rotation length in European forests. Environ Sci Policy 7, 205-219.

Liski, J., Pussinen, A., Pingoud, K., Mäkipää, R., Karjalainen, T., 2001. Which rotation length is favourable to carbon sequestration? Can. J. For. Res. 31 (11), 2004-2013.

Loisel, P., 2011. Faustmann rotation and population dynamics in the presence of a risk of destructive events. J. For. Econ. 17 (3), 235-247.

Loisel, P., 2014. Impact of storm risk on Faustmann rotation. Forest Policy Econ. 38, 191-198.

Loisel, P., Dhôte, J.F., 2011. A tree-growth model to optimize silviculture. Nonlinear
Analysis: Real World Applications 12 (5), 2784-2793.

Möllmann, T.B., Möhring, B., 2017. A practical way to integrate risk in forest management decisions. Ann. For. Sci. 74, 75.

Plantinga, A.J., Birdsey, R.A., 1994. Optimal forest stand management when benefits are derived from carbon. Nat. Resour. Model. 8 (4), 373-387.

Price, C., 2011. When and to what extent do risk premia work? Cases of threat and optimal rotation. J. For. Econ. 17 (1), 53-66.

Price, C., Willis, R., 2011. The multiple effects of carbon values on optimal rotation. Journal of Forest Economics 17 (3), 298-306.

Rakotoarison, H., Loisel, P., 2017. The Faustmann model under storm risk and price uncertainty: a case study of European beech in Northwestern France. Forest Policy Econ. 81, 30-37.

Reed, W.J., 1984. The effects of the risk of fire on the optimal rotation of a forest. J. Environ. Econ. Manag. 11 (2), 180-190.

Reineke, L.H., 1933. Perfecting a stand-density index for even-aged forest. J. Agric. Res. 46, 627-638.

Schmidt, M., Hanewinkel, M., Kandler, G., Kublin, E., Kohnle, U., 2010. An inventorybased approach for modeling single-tree storm damage - experiences with the winter storm of 1999 in southwestern Germany. Can. J. For. Res. 40, 1636-1652.

Schreuder, G.F., 1971. The simultaneous determination of optimal thinning schedule and rotation for an even-aged forest. For. Sci. 17 (3), 333-339.

Sethi, S.P., Thompson, G.L., 2000. Optimal Control Theory. Springer.

Staupendahl, K., Möhring, B., 2011. Integrating natural risks into silvicultural decision models: a survival function approach. Forest Policy Econ. 13 (6), 496-502.

Susaeta, A., Chang, S.J., Carter, D.R., Lal, P., 2014. Economics of carbon sequestration under fluctuating economic environment, forest management and technological changes: an application to forest stands in the southern United States. J. For. Econ. 20 (1), 47-64.

Van Kooten, G.C., Binkley, C.S., Delcourt, G., 1995. Effect of carbon taxes and subsidies on optimal forest rotation age and supply of carbon services. Am. J. Agric. Econ. 77 (2), 365-374. 